schränkt sich auf einige wenige Titel. Durch eine straffere Spezialisierung hätte der Umfang und damit auch der (ohnehin schon subventionierte) recht hohe Preis erheblich reduziert werden können, ohne daß dadurch der Informationswert dieser Bibliographie wesentlich gesunken wäre.

Rolf Hanisch

Klaus Helmstedt (Bearb.)

Elfenbeinküste. Der 7. Parteikongreß der PDCI-RDA und die Wahlen 1980. Eine Pressedokumentation

Dokumentations-Leitstelle Afrika, Aktueller Informationsdienst Afrika-Hamburg, Beiheft 1, 1981, 102 S., DM 8,-

Die Hamburger Dokumentationsleitstelle hat ihre überaus nützliche Arbeit, die sie zusammen mit ihren regionalen Schwesterinstituten im Bereich der bibliographischen Dokumentation leistet, um ein weiteres Tätigkeitsfeld erweitert, das, sollte es weiter ausgedehnt werden, der Afrika- bzw. Entwicklungsländerforschung eine gleichfalls unschätzbare Hilfe sein wird. $\mathrm{Zu}$ einem begrenzten, wichtigen Thema werden hier afrikanische Zeitungen und Presseberichte dokumentiert - im vorliegenden Fall der Fraternité Matin, Abidjan. Diese enthält neben kürzeren Berichten und Analysen wertvolle Primärquellen-, Gesetzestexte, programmatische Reden im Wortlaut, detaillierte Wahlstatistiken usw. All dies ist im vorliegenden Fall übersichtlich zusammengestellt und von dem Bearbeiter durch eine knappe Einführung zusammengefaßt und strukturiert worden.

Rolf Hanisch

\title{
Henning Melber
}

Schule und Kolonialismus: Das formale Erziehungswesen Namibias.

Institut für Afrika-Kunde, Hamburg, 1979, 319 S., DM 23,-

Bei der vorliegenden Arbeit handelt es sich um eine ideologiekritische Situationsanalyse des Bildungswesens in Namibia, die sich als Grundlagenforschung für zukünftige politische Entscheidungsprozesse versteht und sich explizit von einem Anspruch bildungsplanerischer Trendextrapolationen distanziert, die nachgewiesenermaßen häufig nur Pseudoexaktheit vorspiegeln.

Im ersten Kapitel stellt Melber die historische Entwicklung des formalen Erziehungssystems in Namibia bis Mitte der 60er Jahre dar: Die Anfänge der Bildungsarbeit christlicher Missionen; die Bildungspolitik der deutschen Kolonialmacht, in der die Trennung von Weißen- und "Eingeborenenerziehung angelegt wurde, die auch von der südafrikanischen Mandatsverwaltung übernommen und durch die Trennung von Missionsschulen für "Farbige" und "Eingeborene" im Jahre 1925 noch weiter ausgefächert wurde sowie die "Südafrikanisierung" des Schulwesens für Weiße. 
Das zweite Kapitel ist der Analyse der burischen Herrschaftsideologie und ihrer Auswirkungen - auch - auf das namibische Bildungswesen gewidmet. Zur Veranschaulichung dieser Ideologie, die sich im Prinzip der "christlich-nationalen Erziehung " niederschlägt, führt der Autor sinnvollerweise zahlreiche Zitate auf, die deutlich die religiös verbrähmten, soziale und ökonomische Ungleichheit absichernden rassistischen Herrschaftsmomente dieser Doktrin aufzeigen. Abschließend stellt er dar, inwieweit der 1954 in Kraft getretene Bantu Education Act die Apartheid-Ideologie offiziell und verbindlich im Bildungswesen verankert und konkret in der Gestaltung des afrikanischen Unterrichtswesens und der Lehrpläne, die mit leichten Modifikationen auch auf Namibia übertragen werden, festschreibt.

Das dritte Kapitel liefert eine Bestandsaufnahme der Spezifika des namibischen Bildungswesens bis 1978. Die systematische Abhandlung der drei Bildungssektoren - für Weiße, für "Mischlinge" (Coloureds, Rohobother Baster und Nama) sowie für Afrikaner -, die minutiöse Darstellung ihrer jeweiligen Infrastruktur (materielle, finanzielle und personelle Ressourcen) und ihrer Effizienz sowie die unterschiedlichen fachspezifischen und tertiären Weiterbildungsmöglichkeiten, veranschaulicht und abgesichert durch eine Vielzahl von Tabellen, mögen für den Leser etwas ermüdend sein. Dennoch, die Mühe lohnt sich, da Melber nicht, wie häufig in thematisch ähnlichen Studien der Fall, unreflektiert Daten aneinanderreiht, sondern ihren politischen und sozio-ökonomischen Stellenwert sorgfältig-kritisch in bezug zum Herrschaftssystem interpretiert, dem Leser aber auch gleichzeitig mit dem Datenmaterial Möglichkeiten der Uberprüfung seiner Auslegungen an die Hand gibt. Besondere Beachtung verdient das an verschiedenen Stellen überzeugend nachgewiesene Argument, daß weine landesweite Umgestaltung bzw. Neugestaltung der schulischen Ausbildungsverhältnisse ... weder vor dem weißen Bildungssektor halt machen [darf] noch diesen als Zielvorstellung für die Mehrheit der Bevölkerung abzeptabel erscheinen lassen" (S. 121), denn er "ist nur Bestandteil einer anachronistischen Gesellschaftsordnung, die in Verbindung mit einer spezifischen Herrschaftsideologie Gewaltverhältnisse aufrechterhält und produziert" (S. 125). Ebenso differenziert versteht Melber die Formen politischen Bewußtseins und antikolonialen Engagements innerhalb der Mischlingsbevölkerung sowie unter der schwarzen Lehrer- und Schülerschaft in ihren Kausalbeziehungen zum gegenwärtigen gesellschaftlichen Kontext darzustellen.

In seinen Schlußbetrachtungen relativiert der Autor den Stellenwert des Bildungssektors im gesamtgesellschaftlichen Kontext und betont, daß es kaum das Erziehungswesen allein, sondern das Sytem in seiner Gesamtheit ist, "das den Widerstand und das Bewußtsein über die notwendigen Veränderungen bedingt und produziert" (S. 234). Fazit: eine engagiert geschriebene, das eigene wissenschaftliche Vorverständnis of fenlegende und um Ausgewogenheit bemühte Darstellung, die allerdings Vorkenntnisse über die ökonomischen und sozialen Verhältnisse Namibias voraussetzt.

Renate Nestvogel 